\title{
Segurança alimentar e nutricional: cultivo hidropônico como possibilidade de produção alimentícea no semiárido
}

\section{Food and nutritional security: hydroponic cultivation as a possibility of food production in the semi-arid}

\author{
DOI: $10.46814 /$ lajdv2n6-022
}

Recebimento dos originais: 01/09/2020

Aceitação para publicação: 30/10/2020

\author{
Nikolle Nebl Jardim Aravanis \\ Mestre em Sistema de Energia pela International Hellenic University (IHU), pesquisadora do \\ Laboratório de Energia da Universidade do Chipre. \\ E-mail: nikollearavanis@gmail.com \\ Márcia Barros Carvalho Melo \\ Discente do Curso de Engenharia Agrícola e Ambiental da UFRPE, pesquisadora do Gampe. \\ E-mail: marcia.bcmelo@gmail.com
}

\author{
Alexandre N. Santos \\ Mestrando em Engenharia Agrícola e Ambiental da UFRPE. \\ E-mail: alexandrens14@yahoo.com.br
}

\section{Ênio F. França e Silv}

Docente do Curso de Engenharia Agrícola e Ambiental da UFRPE. Pesquisador do INCTSal/CNPq.

E-mail: enio.silva@dtr.ufrpe.br

\section{Soraya Giovanetti El-Dei}

Docente do Curso de Engenharia Agrícola e Ambiental da UFRPE, pesquisadora do Gampe.

E-mail: Sorayaeldeir@pq.cnpq.br

\section{RESUMO}

A Região Semiárida Nordestina é marcada por um quadro de escassez hídrica, a qual afeta a qualidade de vida da população, causando perdas sociais e econômicas significantes. Este contexto também penaliza a produção agrícola, provocando uma diminuição na capacidade produtiva, e consequentemente comprometendo o nível de renda de parte da população. As longas estiagens características da região levam a diminuição do nível dos reservatórios, o que penaliza a agricultura irrigada. Este contexto de escassez hídrica faz com que a captação de água seja realizada por outras fontes, como as subterrâneas. Entretanto estas águas podem apresentar salinidade acima do recomendável ao consumo humano. Desta forma, o uso se dessalinizadores é uma constante, sendo o descarte de seu rejeito ultrassalino um problema ambiental, levando a salinização do solo. No Município de Ibimirim, Sertão do Moxotó de Pernambuco, cultivos hidropônicos com rejeitos de dessalinizadores foram realizados, testando a tolerância de hortaliças aos sais. O presente escrito objetiva analisar o potencial do cultivo hidropônico com bases nestes estudos como alternativa a segurança alimentar no semiárido brasileiro.

Palavras-chave: Hidroponia, Segurança hídrica, Impacto ambiental, Produção alternativa. 


\section{ABSTRACT}

The Northeastern Semi-Arid Region is marked by a situation of water scarcity, which affects the quality of life of the population, causing significant social and economic losses. This context also penalizes agricultural production, causing a decrease in productive capacity, and consequently compromising the income level of part of the population. The long droughts characteristic of the region lead to a decrease in the level of reservoirs, which penalizes irrigated agriculture. This context of water scarcity means that water is collected from other sources, such as underground sources. However, these waters may present salinity above that recommended for human consumption. In this way, the use of desalinators is a constant, and the disposal of its ultra-saline waste is an environmental problem, leading to soil salinization. In the municipality of Ibimirim, Sertão do Moxotó de Pernambuco, hydroponic cultivation with desalinator waste was carried out, testing the tolerance of vegetables to salts. This paper aims to analyze the potential of hydroponic cultivation based on these studies as an alternative to food security in the Brazilian semiarid region.

Keywords: Hydroponics, Water security, Environmental impact, Alternative production.

\section{INTRODUÇÃO}

O Semiárido nordestino apresenta quadro de escassez hídrica, que afeta a qualidade de vida da população, com perdas sociais e econômicas, comprometendo a produção agrícola e a capacidade produtiva, diminuindo a renda de parte da população. As longas estiagens características da região levam a diminuição dos níveis dos reservatórios, o que penaliza a agricultura irrigada. A perfuração de poços é uma das alternativas para captação hídrica, entretanto estas águas, na maioria das vezes podem apresentar salinidade acima do recomendável ao consumo humano. Desta forma, o uso se dessalinizadores é uma constante, sendo o descarte de seu rejeito ultrassalino um problema ambiental, levando a salinização do solo. No Município de Ibimirim, Sertão do Moxotó de Pernambuco, cultivos hidropônicos com rejeitos de dessalinizadores foram realizados, testando a tolerância de hortaliças aos sais.

\section{OBJETIVOS}

O presente escrito tem por objetivo analisar, com base em pesquisas realizadas, o potencial do cultivo hidropônico com o uso de águas residuárias de dessalinizadores no Município de Ibimirim $\mathrm{PE}$, como alternativa a segurança alimentar dos agricultores familiares no semiárido brasileiro.

\section{METODOLOGIA}

Experiência consistiu no cultivo hidropônico de alface e rúcula em canos de PVC, pelo sistema NFT. Esses canos detinham de uma leve inclinação para favorecer o fluxo da solução nutritiva composta de água pura e de nutrientes dissolvidos de forma balanceada para atender as 
necessidades nutricionais da espécie vegetal. Com 15 dias, transplantou as mudas para tubos PVC maiores, onde se monitorou periodicamente a concentração de nutriente na folha e o pH do alface, analisando o controle rigoroso da solução nutritiva para manter as condições de adaptações as características do semiárido. Após 25 dias, as transplantou para vasos que com substratos, objetivando evitar a evaporação da solução nutritiva. Com 45 dias é realizada a colheita de alface, retirando amostras para analise laboratorial de concentração dos nutrientes. Realizou-se experimentos, simulando as águas da região, com tomate, agrião.

\section{RESULTADOS E DISCUSSÃO}

As melhores espécies para o cultivo hidropônico são as de menor porte e a melhor temperatura para esses cultivos é entre 17 a $24^{\circ} \mathrm{C}$ (Alberoni, 1998). Percebeu-se a água subterrânea salobra apresentou viabilidade de uso para produção hidropônica da alface mas a água residuária de sua dessalinização proporcionou baixas produções e sintomas foliares que não justificariam seu aproveitamento comercial. (SOARES et al, 2007; SANTOS et al., 2010; ALVES et al., 2011). Para viabilizar a disseminação do uso de centros hidropônicos como meio de reuso de águas salinas, foi estruturada uma unidade demonstrativa no Centro de Educação Ambiental do Semiárido de Pernambuco, entidade parceira da UFRPE localizada no município de Ibimirim. Nesta estão programados cursos e oficinas sobre hidroponia visando capacitar agricultores familiares e influenciar as instâncias governamentais.

\section{CONSIDERAÇÕES FINAIS}

O cultivo hidropônico de hortaliças é viável e pode se configurar numa política publica voltada para a segurança alimentar e nutricional no semiárido nordestino. Existe uma necessidade de maior divulgação da técnica hidropônica, assim como formação de pessoal técnico para dar suporte extensionistas. Por meio da unidade demonstrativa de hidroponia que está no CEASAPE, a UFRPE busca realizar atividades extensionistas, assim como desta forma cumpre sua obrigação quanto a tríade da atividade acadêmica. Além do mais, observa-se o potencia desta tecnologia social de se tornar uma política pública por parte das instancias governamentais federal, estaduais e municipais, viabilizando a implantação desta em diversos pontos do semiárido nordestino. 


\section{BIBLIOGRAFIA}

ALBERONI, R. B. Hidroponia. São Paulo: Nobel, 1998. 102p.

ARAÚJO et al. Forragem hidropônica de milho cultivado em bagaço de cana e vinhoto.

Revista Brasileira de Milho e Sorgo, v.7, n.3, p. 251-264, 2008.

EL-DEIR, S. G. Metodologias inovadoras para o empoderamento social. Recife: Edufrpe, 2013.

SANTOS, A. N.; SOARES, T. M; SILVA, E. F. F.; SILVA, D. J. R.; MONTENEGRO, A. A. A. Cultivo hidropônico de alface com água salobra subterrânea e rejeito da dessalinização em Ibimirim, PE. Revista brasileira de Engenharia Agrícola Ambiental vol.14 no.9 Campina Grande Sept. 2010

SOARES, T. M.; SILVA, E. F. F.; DUARTE, S. N.; MELO, R. F.; JORGE, C. A.; Bonfim-Silva, E. M. Produção de alface utilizando águas salinas em sistema hidropônico. Revista Irriga, v.12, n.2, p.235-248, 2007. 